\title{
BMJ Open Trends in occurrence and 30-day mortality of infective endocarditis in adults: population-based registry study in Finland
}

\author{
Elina Ahtela, ${ }^{1}$ Jarmo Oksi, ${ }^{1}$ Pekka Porela, ${ }^{2}$ Tommi Ekström, ${ }^{2}$ Paivi Rautava, ${ }^{3,4}$ \\ Ville Kytö ${ }^{2,5}$
}

To cite: Ahtela E, Oksi J, Porela P, et al. Trends in occurrence and 30-day mortality of infective endocarditis in adults: population-based registry study in Finland. BMJ Open 2019;9:e026811. doi:10.1136/ bmjopen-2018-026811

- Prepublication history for this paper is available online. To view these files, please visit the journal online (http://dx.doi org/10.1136/bmjopen-2018026811).

Received 25 September 2018 Revised 17 February 2019 Accepted 1 March 2019

Check for updates

(c) Author(s) (or their employer(s)) 2019. Re-use permitted under CC BY-NC. No commercial re-use. See rights and permissions. Published by BMJ.

${ }^{1}$ Infectious Diseases, Turku University Hospital, Turku, Finland

${ }^{2}$ Heart Center, Turku University Hospital, Turku, Finland ${ }^{3}$ Clinical Research Centre, Turku University Hospital, Turku, Finland

${ }^{4}$ Department of Public Health, University of Turku, Turku,

Finland

${ }^{5}$ Research Center of Applied and Preventive Cardiovascular Medicine, University of Turku, Turku, Finland

Correspondence to

Dr Ville Kytö; ville.kyto@utu.fi

\section{ABSTRACT}

Objectives Infective endocarditis (IE) is a life-threatening disease associated with significant mortality. We studied recent temporal trends and age and sex differences in the occurrence and short-term mortality of IE.

Design Population based retrospective cohort study. Setting Data of IE hospital admissions in patients aged $\geq 18$ years in Finland during 2005-2014 and 30-day allcause mortality data were retrospectively collected from mandatory nationwide registries from 38 hospitals. Outcomes Trends and age and sex differences in occurrence. Thirty-day mortality.

Results There were 2611 cases of IE during the study period (68.2\% men, mean age 60 years). Female patients were significantly older than males (62.0 vs 59.0 years, $\mathrm{p}=0.0004)$. Total standardised annual incidence rate of IE admission was 6.33/100 000 person-years. Men had significantly higher risk of IE compared with women (9.5 vs 3.7/100 000; incidence rate ratios [IRR] 2.49; $\mathrm{p}<0.0001)$ and difference was most prominent at age $40-59$ years (IRR 4.49; $p<0.0001$ ). Incidence rate varied from 5.7/100000 in 2005 to 7.1/100 000 in 2012 with estimated average $2.1 \%$ increase per year $(p=0.036)$ and similar trends in both sexes. Significant increasing trend was observed in patients aged 18-29 years and $30-39$ years (estimated annual increase $7.6 \%$ and $7.2 \%$, $\mathrm{p}=0.002$ ) and borderline in patients aged $40-49$ years (annual increase $3.8 \%, p=0.08$ ). In older population, IE incidence rate remained stable. The overall 30-day mortality after IE admission was $11.3 \%$. Mortality was similar between sexes, increased with ageing, and remained similar during the study period.

Conclusions Occurrence of IE is increasing in young adults in Finland. Men, especially middle-aged, are at higher risk for IE compared with women. Thirty-day mortality has remained stable at $11 \%$, increased with ageing, and was similar between sexes.

\section{INTRODUCTION}

Infective endocarditis (IE) is a life-threatening disease associated with high morbidity and mortality. The incidence of IE has reported to be $2-8$ cases per 100000 person-years. ${ }^{1-9}$ Previous studies have found the incidence
Strengths and limitations of this study

- Nationwide, population-based study on occurrence and short-term mortality of infective endocarditis in Finland.

- Decade long population coverage (over 42 million person-years), using mandatory nationwide registries.

- The data are extracted from medical records: the availability of the data depends on the completeness and detail of the medical record.

- Retrospective design without access to detailed clinical data.

of IE to be increasing in Europe $\mathrm{e}^{5-7} 10$ while in the USA, both stable ${ }^{811}$ and increasing IE rate $^{1213}$ have been described. The epidemiologic profile of IE is changing due to population changes such as lengthening of life expectancy, change in risk factors and development of diagnostic methods. Furthermore, people are exposed to increasing amount of healthcare procedures. ${ }^{714}$ Increasing number of cardiac procedures with implanted prosthetic material is associated with increasing IE incidence. ${ }^{8}{ }^{15-19}$ Improved survival of the patients with a predisposing factor to severe bacterial infections, such as congenital heart disease or prosthetic heart valve may also contribute to the IE incidence. ${ }^{20}$ The shortterm mortality of IE has been reported to be 10\%-24\%. ${ }^{35718}$ Despite the development of treatment methods, the majority of studies have found short-term mortality to be stable over the last years ${ }^{5} 1218$ although trend for increased mortality is also reported. ${ }^{7}$ Population-based sex-specific and age-specific epidemiology and trends of IE are however inadequately known. The purpose of this nationwide study was to study recent temporal 
trends and age and sex differences in the occurrence and short-term mortality of IE in Finland.

\section{METHODS}

\section{Study design and data collection}

This population-based study included adult patients ( $\geq 18$ years of age) hospitalised for IE in Finland during 2005-2014. Data were collected retrospectively from the nationwide Care Register for Health Care (CRHC) database maintained by the Finnish National Institute for Health and Welfare. ${ }^{21}$ This obligatory database automatically collects hospital discharge data including individual baseline data (eg, age, sex, admission, operation and discharge dates), discharge diagnoses (International Classification of Diseases [ICD]-10) and operational codes (Nordic Classification of Surgical Procedures) of all hospital admissions in Finland. Each individual in Finland has unique social security identification number allowing for patient specific data collection and follow-up. We studied patients discharged from medical or surgical care units of all 38 hospitals (including five university hospitals) treating acute IE between 1 January 2005 and 31 December 2014. Surgical operations of the heart or ascending aorta and pacemaker implantations or changes performed 1 year prior to the admission due to IE during study period were recognised from CRHC.

Data of Finnish population at risk (42 754847 personyears) and 30-day mortality data of patients with IE admission were obtained from Statistics Finland.

\section{Definitions}

Patients with discharge diagnosis of IE (ICD-10 codes I33, I38 and I39) as primary (66.3\%), secondary $(24.1 \%)$ or tertiary $(9.6 \%)$ cause of admission were included in the study. One IE admission/patient/year was included. The annual incidence rate of admissions per calendar year was calculated using age-specific, year-specific and sex-specific population data and standardised with European 2013 standard population using direct method. Charlson comorbidity index (CCI) score was calculated as previously described. ${ }^{22}$

\section{Validation of infective endocarditis diagnoses}

Specificity of ICD-10 IE codes (I33, I38 or I39) was studied in a subgroup of patients admitted to the Turku University Hospital. Patient records (including, eg, laboratory, microbiology, pathological and imaging data) of randomly selected patients $(\mathrm{n}=188 ; 74 \%$ male, mean age 59.7 years) admitted during 2005-2014 were reviewed to determine whether the modified Duke criteria for $\mathrm{IE}^{23}$ were fulfilled. Of 188 reviewed patients, 182 fulfilled the criteria (definitive IE in 122 and possible IE in 60 patients) resulting to specificity of $96.8 \%$.

\section{Statistical analysis}

Patient characteristics were analysed for included admissions using $\chi^{2}$ and t-tests as appropriate. Negative binomial

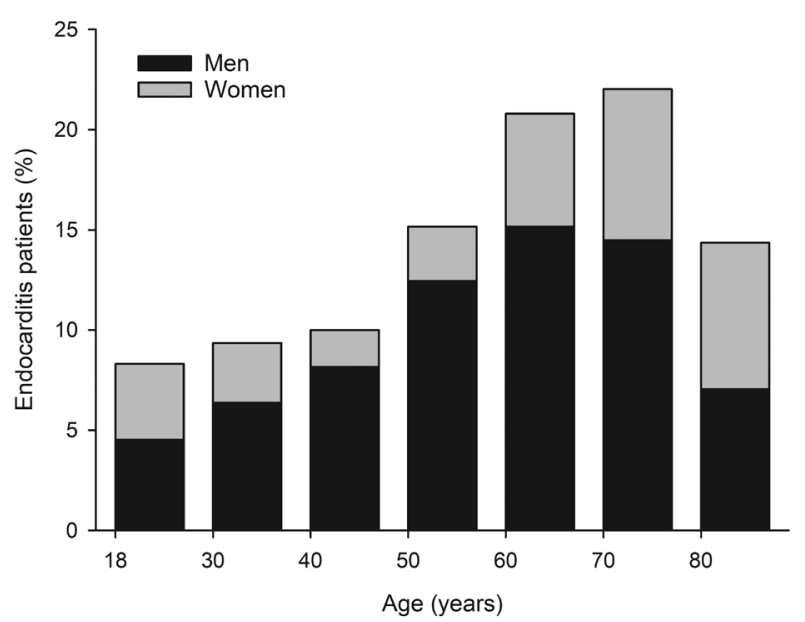

Figure 1 Age distribution of patients with infective endocarditis. Sex-specific distribution is presented as relative proportion within bars.

regression with logarithm of corresponding population as an offset parameter was used for analysis of incidence rates. Incidence rate ratios (IRR) were estimated using regression models with number of admissions as dependent variable and sex, age and year of admission as independent variables. Mortality of first IE admission in study period was studied with Cox regression modelling. Potential association modifications by age, sex and study year were studied with interaction analyses. Variables associated with mortality at significance level of $\mathrm{p}<0.2$ in univariate analysis were included in multivariate Cox modelling. Otherwise $\mathrm{p}<0.05$ was considered statistically significant. Statistical analyses were performed with the SAS system V.9.4.

\section{Patient and public involvement}

Patients or public were not involved in the design or conduction of this study.

\section{RESULTS}

\section{Patient characteristics}

There were 2611 IE admissions occurring to 2331 individuals in the study period. Of IE admissions, 1780 (68.2\%) occurred to men and $831(31.8 \%)$ to women. The mean age of the patients with IE was 60.0 years (SD 18.3, range 18-97) (figure 1). Women with IE were older than men (mean age 62.0 SD 20.7 vs 59.0 SD 17.1, $\mathrm{p}=0.0004$ ) and had higher comorbidity burden (CCI score $\geq 1$ in $46.7 \%$ vs $42.5 \%$ in men, $\mathrm{p}=0.047$ ). Within 1 year prior to admission with IE, $7.8 \%$ of patients had open cardiac surgery, prosthetic valve was implanted in $5.5 \%$ and $0.8 \%$ underwent coronary artery bypass grafting. Pacemaker was implanted or pacemaker generator changed in $1.5 \%$ of patients within 1 year before IE admission.

\section{Occurrence}

The crude annual incidence rate of IE admissions was 6.11 cases per 100000 person-years (95\% CI 5.86 to 6.36) and 

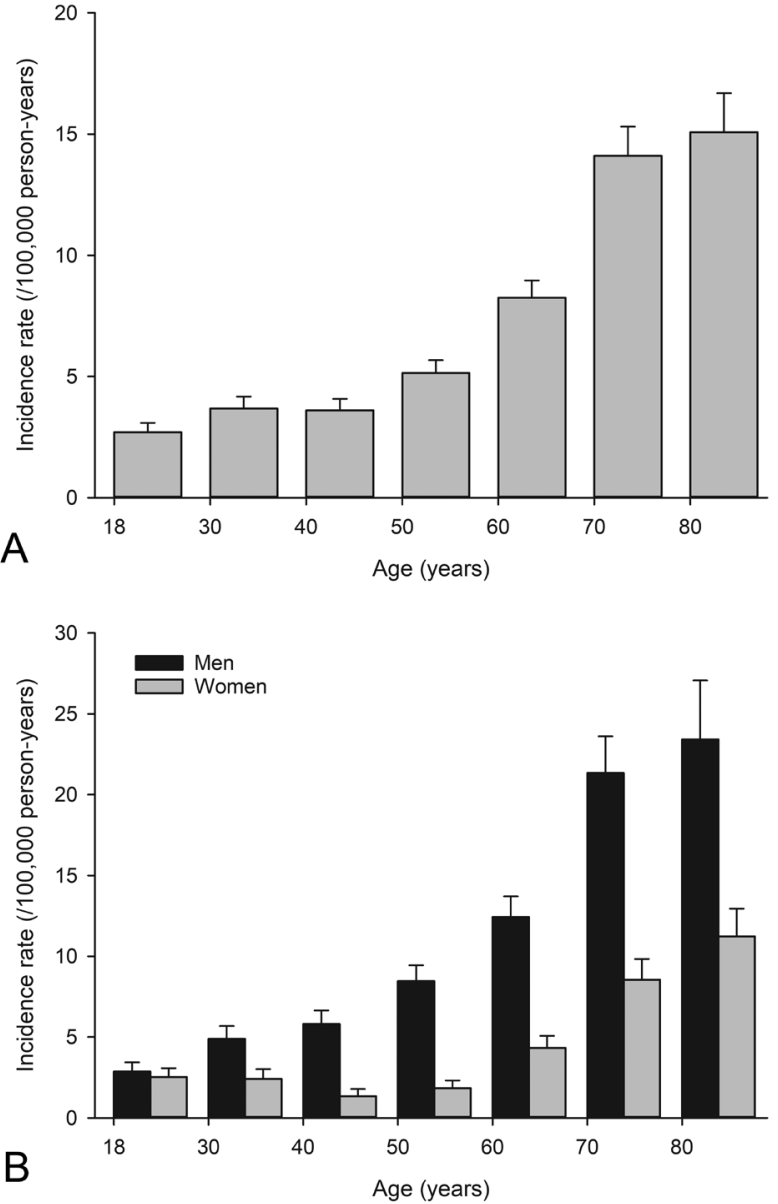

Figure 2 Occurrence of infective endocarditis admissions in general adult population. Total $(A)$ and sex-specific (B) annual incidence rates (per 100000 person-years) by age. Error bars represent upper limits of $95 \% \mathrm{Cl}$.

standardised incidence rate was 6.33 cases per 100000 person-years (95\% CI 6.09 to 6.57). The crude incidence rate in men was 8.57 cases per 100000 person-years $(95 \%$ $\mathrm{Cl} 8.18$ to 8.98$)$ and 3.78 cases per 100000 person-years in women (95\% CI 3.53 to 4.04). Standardised rates were 9.46 cases per 100000 person-years (95\% CI 9.04 to 9.89 ) in men and 3.67 cases per 100000 person-years (95\% CI 3.45 to 3.94 ) in women. Overall incidence rate of IE was lowest in youngest study population, somewhat higher in population aged 30-49 years and increased progressively with age in older population (figure 2 ). In men, IE incidence rate increased more steadily with ageing than in women. Increasing IE incidence rate was observed beginning from 60 years of age in women (figure 2). Men had significantly higher risk of IE compared with women overall (IRR 2.49; CI 2.22 to 2.79; $\mathrm{p}<0.0001$ ). Sex difference in IE risk was present in patients aged $\geq 30$ years, was most prominent in population aged $40-59$ years (IRR 4.49; CI 3.68 to $5.48 ; \mathrm{p}<0.0001)$ and decreased thereafter (figure 3 ).

\section{Annual trends}

The total incidence rate of IE admissions varied from $5.71 / 100000$ in 2005 to $7.08 / 100000$ in 2012 with

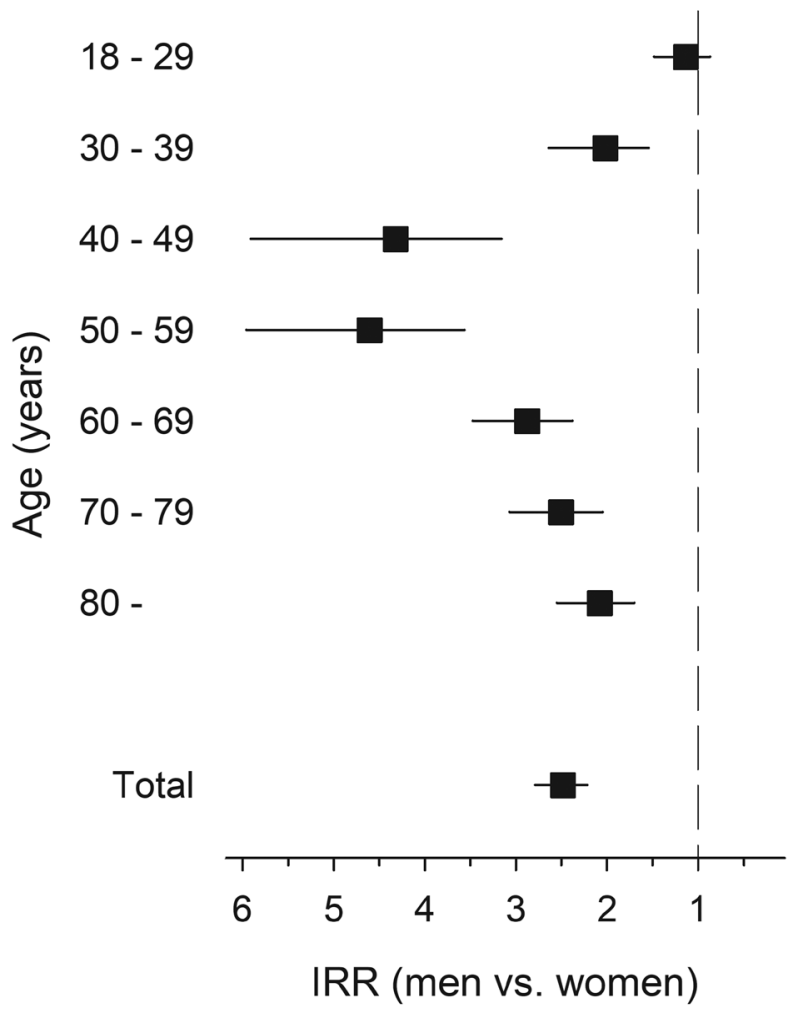

Figure 3 Sex differences in relative risk for infective endocarditis by age in general adult population. Error bars represent $95 \% \mathrm{Cl}$. IRR, incidence rate ratio.

estimated average increase of $2.13 \%$ per year (IRR 1.021; $95 \%$ CI 1.002 to $1.042, \mathrm{p}=0.035$ ) during the study period (figure 4). Overall incidence trend was similar between sexes (interaction $\mathrm{p}=0.725$ ). There was however a significant difference in evolution of IE admission trends regarding age (interaction $\mathrm{p}=0.003$, table 1 ). Increase in IE occurrence was driven by significant $7.2 \%-7.6 \%$ annual increase in population aged $18-39$ years $(p=0.002)$. In population aged $40-49$, there was a $3.8 \%$ annual change in occurrence $(\mathrm{p}=0.08)$. In older population, however, there was no clear trend during study period in IE

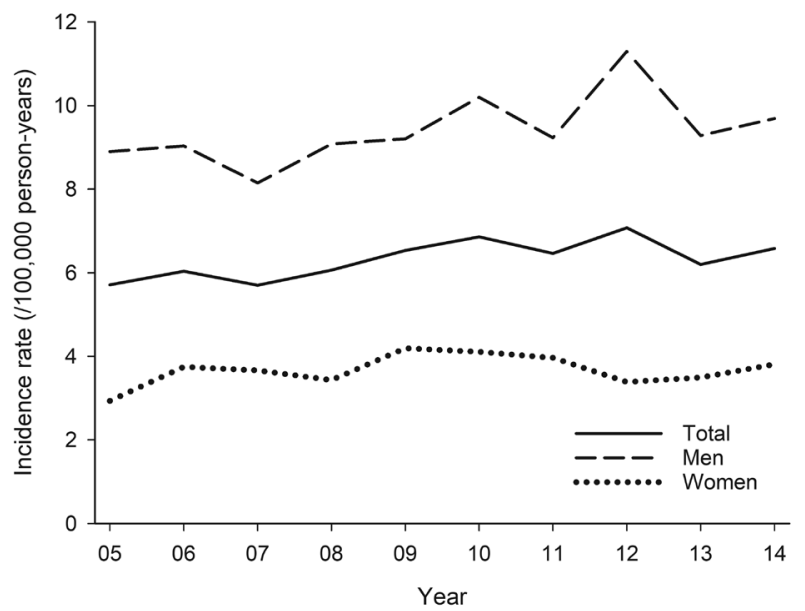

Figure 4 Trends in annual incidence rate of infective endocarditis rate in general adult population. 


\begin{tabular}{|c|c|c|c|}
\hline Age (years) & $\begin{array}{l}\text { Estimated annual } \\
\text { change } \%\end{array}$ & $95 \% \mathrm{Cl}$ & $P$ value \\
\hline $18-29$ & 7.62 & 2.67 to 12.81 & 0.002 \\
\hline $30-39$ & 7.24 & 2.61 to 12.07 & 0.002 \\
\hline $40-49$ & 3.82 & -0.50 to 8.32 & 0.084 \\
\hline $50-59$ & 0.52 & -2.60 to 4.01 & 0.767 \\
\hline $60-69$ & 0.20 & -2.75 to 3.18 & 0.910 \\
\hline $70-79$ & -2.05 & -5.39 to 1.42 & 0.244 \\
\hline $80-$ & 1.32 & -2.23 to 5.00 & 0.470 \\
\hline Total $^{\star}$ & 2.13 & 0.15 to 4.15 & 0.035 \\
\hline
\end{tabular}

${ }^{*}$ Adjusted for age.

incidence rate. Proportion of patients with prosthetic valve surgery or pacemaker operation within 1 year prior to IE varied by study year (figure 5) but had no significant trend ( $\mathrm{p}=\mathrm{NS}$ for both). Comorbidity burden (CCI score) remained also similar during study period.

\section{Short-term mortality}

Thirty-day all-cause mortality after IE admission was $11.3 \%$. Mortality increased significantly with ageing (figure 6 , table 2 ). In patients aged $<50$ years mortality was $4.8 \%$, in patients aged $50-69$ years mortality was $10.9 \%$ with further increase to $16.0 \%$ in the oldest ( $>70$ years) patients $(p<0.0001)$. Age difference in mortality was similar in both sexes (interaction $\mathrm{p}=0.145$ ). Mortality was similar between men and women (table 2 ). There was no significant annual trend for 30-day mortality with similar occurrence in both sexes and different age groups (interaction $\mathrm{p}>0.65$ for both). Thirty-day mortality increased with comorbidity burden (CCI) but was similar regardless of prosthetic valve implantation or pacemaker operation a year prior to IE (table 2 ).

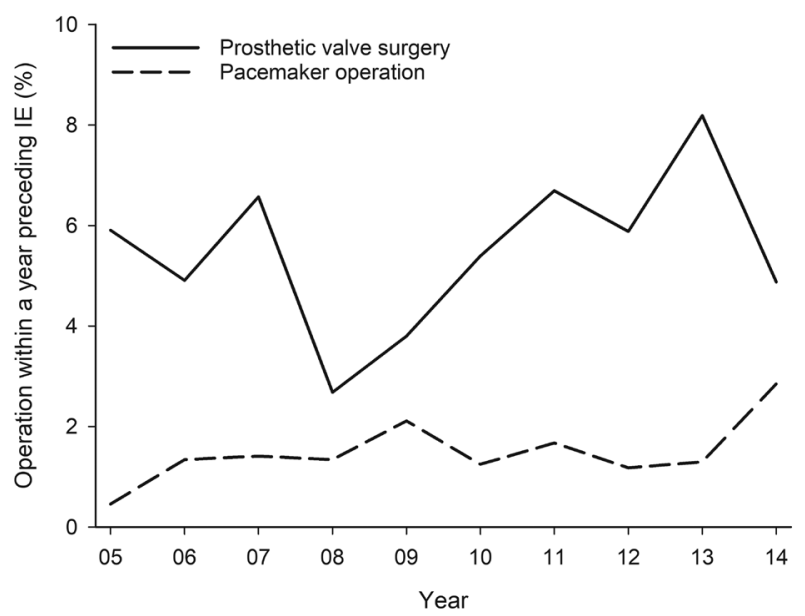

Figure 5 Trends of prosthetic valve surgery and pacemaker operations within a year prior to infective endocarditis admission.
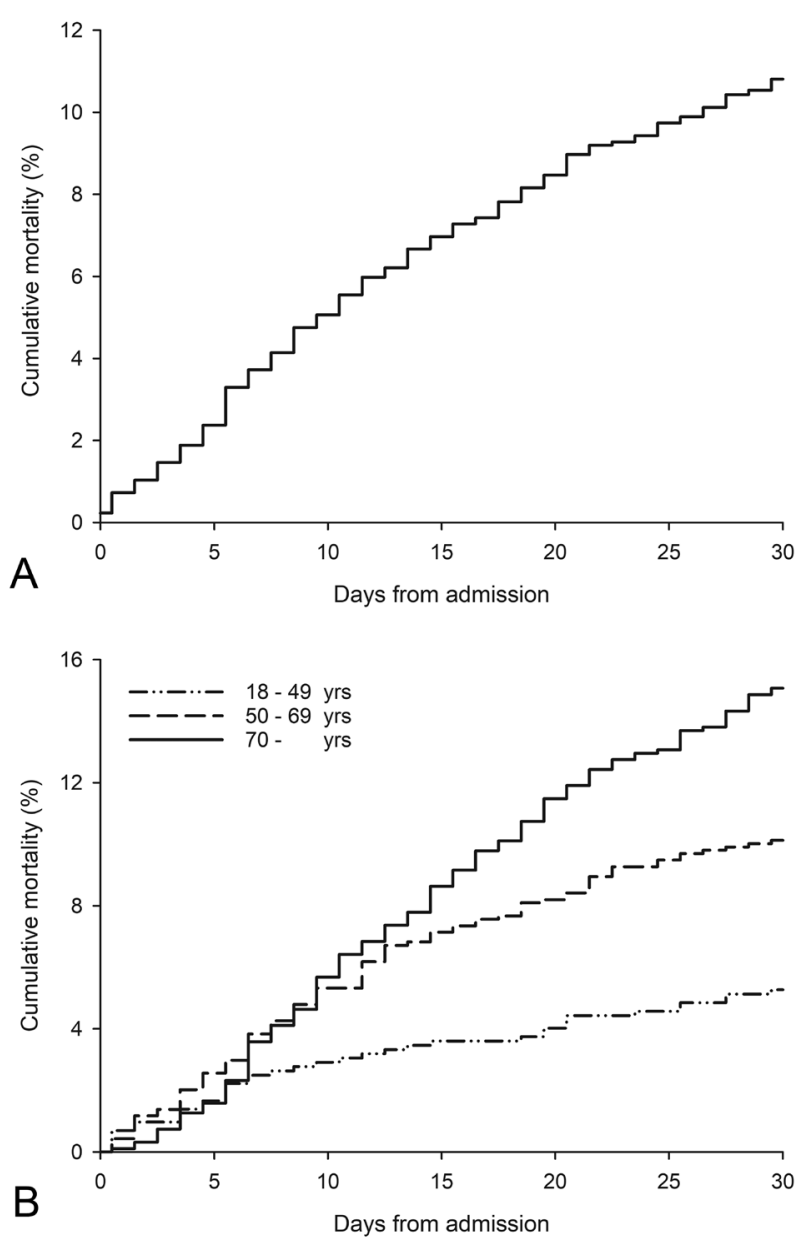

Figure 6 Cumulative total $(A)$ and age-stratified (B) all-cause 30-day mortality after infective endocarditis admission.

\section{DISCUSSION}

This nationwide population-based study explored temporal trends and age and sex differences in the occurrence and short-term mortality of IE in general adult population. The standardised incidence rate of IE admissions was 6.3 cases per 100000 person-years in Finland. This is in concordance with previous studies from other Western countries reporting incidence rates of 2-8 per 100000 person-years. ${ }^{1-9}$ The likelihood of IE in our study was lowest in the youngest study population, somewhat higher in population aged 30-49 years and increased progressively with age in older population. This is likely to be related with the higher risk for degenerative valve diseases and coexisting medical conditions predisposing to severe bacterial infections ${ }^{20}$ in older patients.

We found the occurrence of IE to be rising in adults $<40-50$ years and this reflects to an increase of the overall IE incidence rate. However, in older population there was no significant trend in IE occurrence. Curiously, studies from US, Denmark and Spain have reported contradictory results with increasing IE rates in older patients. ${ }^{612} 24$ Reason for this discrepancy remains to be determined. One plausible explanation might be increasing drug abuse among young Finnish adults. ${ }^{25} 26$ The mean age of the patients with IE in our study was 60 
Table 2 Predictors of 30-day all-cause mortality after first infective endocarditis admission during study period ( $\mathrm{n}=2331)$

\begin{tabular}{|c|c|c|c|c|}
\hline \multirow[b]{2}{*}{ Parameter } & \multicolumn{2}{|l|}{ Univariate models } & \multicolumn{2}{|l|}{ Multivariate model } \\
\hline & HR (95\% Cl) & P value & HR $(95 \% \mathrm{Cl})$ & P value \\
\hline Female sex & 1.19 (0.93 to 1.53$)$ & 0.170 & 1.09 (0.84 to 1.40$)$ & 0.532 \\
\hline $18-49$ & Reference & & Reference & \\
\hline $50-69$ & 2.34 (1.55 to 3.58$)$ & $<0.0001$ & 2.05 (1.35 to 3.13$)$ & 0.001 \\
\hline Charlson comorbidity index & & $<0.0001$ & & $<0.0001$ \\
\hline 0 & Reference & & Reference & \\
\hline 1 & 2.25 (1.67 to 3.02$)$ & $<0.0001$ & $2.00(1.49$ to 2.70$)$ & $<0.0001$ \\
\hline$\geq 2$ & 2.83 (2.11 to 3.79$)$ & $<0.0001$ & 2.40 (1.79 to 3.23$)$ & $<0.0001$ \\
\hline Prosthetic valve implantation* & 0.67 (0.36 to 1.26$)$ & 0.217 & - & \\
\hline
\end{tabular}

*Within a year prior to endocarditis admission.

years. The patients were younger than in several previous population-based studies. ${ }^{235-7}$ This might reflect the easy access to healthcare system for drug abusers in Finland.

Ternhag et $a \tilde{l}$ reported a nationwide study of IE episodes during 1997-2007 based on register data from Sweden. They found IE incidence corresponding to our findings, 7.7/100000, and the incidence rate also increased during the study period. The mean age was 66 years which is higher than in our study. In Denmark in a similar study setting, the incidence rate increased from 3.9 to $7.6 / 100000$ during the study period 1994-2011 with a mean age of 63 years. ${ }^{6}$

Surgical and dental procedures may cause bacteremia linked to IE. Guidelines for IE prophylaxis published by the American Heart Association in $2007^{27}$ and by the European Society of Cardiology in $2009^{28}$ restricted the pre-procedural antibiotic usage. In UK NICE Guidelines of 2008 went a step further with abolishing prophylactic antibiotic usage. ${ }^{29}$ This change has been associated with increased occurrence of IE in the UK, ${ }^{30}$ the Netherlands ${ }^{10}$ and in Germany. ${ }^{18}$ A recent US study showed decrease in prescription of prophylactic antibiotics and concurrent increase in IE among high-risk individuals following guideline change. ${ }^{31}$ Previous studies from the $\mathrm{USA}^{8}$ and Canada ${ }^{32}$ have however found no association of endocarditis prophylaxis guidelines and overall IE occurrence. In agreement, we found occurrence of IE admissions to increase with stable rate between 2005 and 2014 suggesting that guideline changes did not have a major impact to overall occurrence of IE in adult Finnish population. Further studies on antibiotic prophylaxis are however warranted. $^{1331}$

Our results show that IE admissions are more common in men than in women with 2.5 -fold relative risk. This is in line with a recent study of Thornhill et at that found 2.2-fold odds for IE in men and with previous studies. ${ }^{34}$ In our study, the sex difference was most prominent in population aged 40-59 years. One likely explanation for male predominance is the increased number of risk factors ${ }^{9}$ and predisposing medical conditions, such as degenerative valve disease, for IE in men. Furthermore, the intravenous drug use is more common in men. ${ }^{26}{ }^{35}$ Pregnancy-associated endocarditis is likely to contribute for more comparable IE occurrence between sexes in adults $<40$ years. ${ }^{36}$

Prosthetic valve was implanted in $5.5 \%$ of patients and pacemaker was implanted or pacemaker generator changed in $1.5 \%$ of patients within 1 year prior to diagnosis of IE. These proportions varied by year, but no significant trend was observed. Previous studies have found the proportion of IE patients with a history of heart valve surgery or implanted pacemakers increasing. ${ }^{7} 15161819$ Notably, previous prosthetic valve replacement is found to increase the odds of IE approximately 70-fold and implanted pacemaker 10-fold. ${ }^{9}$

The 30-day all-cause mortality for IE was $11.3 \%$ in our study population. This is comparable to 30-day mortality of $10.4 \%$ found in a Swedish IE study. ${ }^{5}$ Previous studies have reported higher in-hospital mortalities. ${ }^{712182437}$ In a study among Medicare beneficiaries, the in-hospital mortality rate for IE was $9.1 \%-11.1 \%$ and 30-day mortality rate $14.2 \%-16.5 \% .{ }^{11}$ We found no significant annual trend for short-term mortality. This is in line with a number of previous studies, ${ }^{51218}$ but trend for increasing short-term mortality has also been reported. ${ }^{7}$ Reason for non-decreasing short-term IE mortality is unclear. It is possible that improved diagnosis of IE in critically ill patients may offset the improvement of treatment methods. Increasing age and comorbidity burden predicted 30-day mortality in our study population. Age was a strong predictor with 2.8-fold adjusted mortality hazard of patients aged $\geq 70$ years compared with $<50$ years old IE patients. Short-term mortality was however similar between sexes in our study 
population, comparably to previous survey of 1980-2004 in Finland. ${ }^{34}$

\section{Strengths and limitations}

The present retrospective study is based on a register database and there are thus certain limitations. The diagnoses were made by the treating physicians and access to the detailed clinical data were not available for all study patients. However, the accuracy of the mandatory and centralised nationwide CRHC registry is found to be valid. ${ }^{38}$ Modified Duke criteria ${ }^{23}$ are the gold standard for IE diagnosis in Finland. In subgroup analysis of IE patients admitted to tertiary university hospital, we found specificity of ICD-10 codes for IE to be $96.8 \%$. Accordingly, a recent validation study using similar methodology found ICD-10 codes for IE to have 90\% sensitivity and $100 \%$ specificity. ${ }^{39}$ It is nevertheless possible that accuracy of ICD-10 codes for IE may differentiate between institutions. We did not have microbiological results of blood or tissue samples of the patients, which limits the conclusions of this study. In addition, risk factors available for analysis were limited (eg, data on intravenous drug use or previous native valve disease were not available). Major strength of our study is the decade long nationwide coverage of total adult population.

\section{CONCLUSIONS}

In conclusion, the occurrence of IE is increasing in young adults, but not in older population in Finland. Men, especially at middle-age, have higher risk for IE than women. The 30-day mortality has remained stable at $11 \%$ and was similar between sexes. Mortality increased significantly with ageing and comorbidities.

Contributors EA prepared the manuscript for which all authors contributed upon. EA, JO, PP and VK planned the study. VK and PR collected the study data. EA, TE and VK analysed the data. VK supervised the study and submitted the manuscript.

Funding This study was supported by governmental VTR-funding of the Hospital District of Southwest Finland, Finnish Cardiac Society, Finnish Cultural Foundation, Finnish Foundation for Cardiovascular Research, Aarne Koskelo Foundation, TYKSfoundation and Rauno and Anne Puolimatka foundation.

Competing interests None declared.

Patient consent for publication Not required.

Ethics approval The study was approved by the Hospital District of Southwest Finland (permission no T02/015/17), National Institute for Health and Welfare (THL/1349/5.05.00/2015) and Statistics Finland (TK53-1410-15).

Provenance and peer review Not commissioned; externally peer reviewed.

Data sharing statement The data and study materials will be made available to those who fulfill the requirements of applicable Finnish laws and regulations for purposes of reproducing the results or replicating the procedure (from the corresponding author).

Open access This is an open access article distributed in accordance with the Creative Commons Attribution Non Commercial (CC BY-NC 4.0) license, which permits others to distribute, remix, adapt, build upon this work non-commercially, and license their derivative works on different terms, provided the original work is properly cited, appropriate credit is given, any changes made indicated, and the use is non-commercial. See: http:// creativecommons.org/licenses/by-nc/4.0/.

\section{REFERENCES}

1. Tleyjeh IM, Abdel-Latif A, Rahbi H, et al. A systematic review of population-based studies of infective endocarditis. Chest 2007;132:1025-35.

2. Correa de Sa DD, Tleyjeh IM, Anavekar NS, et al. Epidemiological trends of infective endocarditis: a population-based study in Olmsted County, Minnesota. Mayo Clin Proc 2010;85:422-6.

3. Selton-Suty C, Célard M, Le Moing V, et al. Preeminence of Staphylococcus aureus in infective endocarditis: a 1-year populationbased survey. Clin Infect Dis 2012;54:1230-9.

4. Duval X, Delahaye F, Alla F, et al. Temporal trends in infective endocarditis in the context of prophylaxis guideline modifications: three successive population-based surveys. J Am Coll Cardiol 2012;59:1968-76.

5. Ternhag A, Cederström A, Törner A, et al. A nationwide cohort study of mortality risk and long-term prognosis in infective endocarditis in Sweden. PLoS One 2013;8:e67519.

6. Erichsen P, Gislason GH, Bruun NE. The increasing incidence of infective endocarditis in Denmark, 1994-2011. Eur J Intern Med 2016;35:95-9.

7. Cresti A, Chiavarelli M, Scalese M, et al. Epidemiological and mortality trends in infective endocarditis, a 17-year population-based prospective study. Cardiovasc Diagn Ther 2017;7:27-35.

8. Toyoda N, Chikwe J, Itagaki S, et al. Trends in Infective Endocarditis in California and New York State, 1998-2013. JAMA 2017;317:1652-60.

9. Thornhill $\mathrm{MH}$, Jones S, Prendergast B, et al. Quantifying infective endocarditis risk in patients with predisposing cardiac conditions. Eur Heart J 2018;39:586-95.

10. van den Brink FS, Swaans MJ, Hoogendijk MG, et al. Increased incidence of infective endocarditis after the 2009 European Society of Cardiology guideline update: a nationwide study in the Netherlands. Eur Heart J Qual Care Clin Outcomes 2017;3:141-7.

11. Bikdeli B, Wang $\mathrm{Y}, \mathrm{Kim} \mathrm{N}$, et al. Trends in hospitalization rates and outcomes of endocarditis among Medicare beneficiaries. J Am Coll Cardiol 2013;62:2217-26.

12. Bor $\mathrm{DH}$, Woolhandler S, Nardin R, et al. Infective endocarditis in the U.S., 1998-2009: a nationwide study. PLoS One 2013;8:e60033.

13. Pant $S$, Patel NJ, Deshmukh A, et al. Trends in infective endocarditis incidence, microbiology, and valve replacement in the United States from 2000 to 2011. J Am Coll Cardiol 2015;65:2070-6.

14. Fernández-Hidalgo N, Almirante $\mathrm{B}$, Tornos $\mathrm{P}$, et al. Contemporary epidemiology and prognosis of health care-associated infective endocarditis. Clin Infect Dis 2008;47:1287-97.

15. Zhan C, Baine WB, Sedrakyan A, et al. Cardiac device implantation in the United States from 1997 through 2004: a population-based analysis. J Gen Intern Med 2008;23(Suppl 1):13-19.

16. Kurtz SM, Ochoa JA, Lau E, et al. Implantation trends and patient profiles for pacemakers and implantable cardioverter defibrillators in the United States: 1993-2006. Pacing Clin Electrophysiol 2010;33:705-11.

17. Greenspon AJ, Patel JD, Lau E, et al. 16-year trends in the infection burden for pacemakers and implantable cardioverter-defibrillators in the United States 1993 to 2008. J Am Coll Cardiol 2011;58:1001-6.

18. Keller K, von Bardeleben RS, Ostad MA, et al. Temporal Trends in the Prevalence of Infective Endocarditis in Germany Between 2005 and 2014. Am J Cardiol 2017;119:317-22.

19. Carrasco F, Anguita M, Ruiz M, et al. Clinical features and changes in epidemiology of infective endocarditis on pacemaker devices over a 27-year period (1987-2013). Europace 2016;18:836-41.

20. Wang HE, Shapiro NI, Griffin R, et al. Chronic medical conditions and risk of sepsis. PLoS One 2012;7:e48307.

21. Arola A, Pikkarainen E, Sipilä JO, et al. Occurrence and Features of Childhood Myocarditis: a Nationwide Study in Finland. J Am Heart Assoc 2017;6:e005306.

22. Quan $\mathrm{H}$, Sundararajan V, Halfon $\mathrm{P}$, et al. Coding algorithms for defining comorbidities in ICD-9-CM and ICD-10 administrative data. Med Care 2005;43:1130-9.

23. Li JS, Sexton DJ, Mick N, et al. Proposed modifications to the Duke criteria for the diagnosis of infective endocarditis. Clin Infect Dis 2000;30:633-8.

24. Olmos C, Vilacosta I, Fernández-Pérez C, et al. The Evolving Nature of Infective Endocarditis in Spain: A Population-Based Study (2003 to 2014). J Am Coll Cardiol 2017;70:2795-804.

25. Kankaanpää A, Ariniemi K, Heinonen M, et al. Current trends in Finnish drug abuse: Wastewater based epidemiology combined with other national indicators. Sci Total Environ 2016;568:864-74.

26. Varjonen V. Huumetilanne Suomessa 2014. Reports of National Institute for Health and Welfare. 2015. In Finnish http://urn.fi/URN: ISBN:978-952-302-414-4 (accessed 5 Apr 2018). 
27. Wilson W, Taubert KA, Gewitz M, et al. Prevention of infective endocarditis: guidelines from the American Heart Association: a guideline from the American Heart Association Rheumatic Fever, Endocarditis, and Kawasaki Disease Committee, Council on Cardiovascular Disease in the Young, and the Council on Clinical Cardiology, Council on Cardiovascular Surgery and Anesthesia, and the Quality of Care and Outcomes Research Interdisciplinary Working Group. Circulation 2007;116:1736-54.

28. Habib G, Hoen B, Tornos P, et al. Guidelines on the prevention, diagnosis, and treatment of infective endocarditis (new version 2009): the Task Force on the Prevention, Diagnosis, and Treatment of Infective Endocarditis of the European Society of Cardiology (ESC). Endorsed by the European Society of Clinical Microbiology and Infectious Diseases (ESCMID) and the International Society of Chemotherapy (ISC) for Infection and Cancer. Eur Heart J 2009;30:2369-413.

29. Stokes T, Richey R, Wray D, et al. Prophylaxis against infective endocarditis: summary of NICE guidance. Heart 2008;94:930-1.

30. Dayer MJ, Jones S, Prendergast B, et al. Incidence of infective endocarditis in England, 2000-13: a secular trend, interrupted timeseries analysis. Lancet 2015;385:1219-28.

31. Thornhill MH, Gibson TB, Cutler E, et al. Antibiotic Prophylaxis and Incidence of Endocarditis Before and After the 2007 AHA Recommendations. J Am Coll Cardiol 2018;72:2443-54.
32. Mackie AS, Liu W, Savu A, et al. Infective Endocarditis Hospitalizations Before and After the 2007 American Heart Association Prophylaxis Guidelines. Can J Cardiol 2016;32:942-8.

33. Hill EE, Herijgers P, Claus P, et al. Infective endocarditis: changing epidemiology and predictors of 6-month mortality: a prospective cohort study. Eur Heart J 2007;28:196-203.

34. Heiro M, Helenius $\mathrm{H}$, Hurme S, et al. Short-term and one-year outcome of infective endocarditis in adult patients treated in a Finnish teaching hospital during 1980-2004. BMC Infect Dis 2007;7:78.

35. Degenhardt L, Peacock A, Colledge S, et al. Global prevalence of injecting drug use and sociodemographic characteristics and prevalence of HIV, HBV, and HCV in people who inject drugs: a multistage systematic review. Lancet Glob Health 2017;5:e119 2-e1207.

36. Kebed KY, Bishu K, Al Adham Rl, et al. Pregnancy and postpartum infective endocarditis: a systematic review. Mayo Clin Proc 2014;89:1143-52.

37. Murdoch DR, Corey GR, Hoen B, et al. Clinical presentation, etiology, and outcome of infective endocarditis in the 21st century: the International Collaboration on Endocarditis-Prospective Cohort Study. Arch Intern Med 2009;169:463-73.

38. Sund R. Quality of the Finnish Hospital Discharge Register: a systematic review. Scand J Public Health 2012;40:505-15.

39. Tan C, Hansen M, Cohen G, et al. Accuracy of administrative data for identification of patients with infective endocarditis. Int $\mathrm{J}$ Cardiol 2016;224:162-4. 